\title{
El retroceso de las libertades sociales en tiempos de pandemia: ¿un punto de inflexión necesario o el camino sin retorno?
}

The decline of social freedoms in times of pandemic: $₫$ a necessary turning point or the path of no return?

O retrocesso das liberdades sociais em tempos de pandemia: ¿um ponto de viragem necessário ou o caminho de não retorno?

\author{
Martiniano Reyes-Olivo \\ mreyesoliv@gmail.com \\ Universidad Nacional Abierta-Venezuela \\ https://orcid.org/0000-0002-9337-046X
}

\begin{abstract}
RESUMEN
Los gobiernos del mundo inspirados en las estrategias de supervisión e inmovilidad social creadas por el autoritarismo chino, son pretexto de combatir la pandemia, han implementado herramientas tecnológicas como la geolocalización, el reconocimiento facial y la manipulación de la Big Data, entre otras, lo que ha fortalecido el abuso sobre las libertades individuales. La presente investigación se llevó a cabo bajo un enfoque cualitativo con una metodología de revisión documental de tipo narrativa, nutriéndose de fuentes de información primaria y secundaria. El diseño fue de corte transversal ubicado en el año 2020 con un nivel no experimental. Este trabajo, tuvo por objetivo conocer el estado actual de las libertades sociales a nivel global como consecuencia de la aplicación de estrategias de control y de inmovilidad social en la lucha contra el virus Covid-19. Se encontró una tendencia hacia la baja del índice de Libertades sociales en el mundo tanto en países con gobiernos autoritarios como aquellos denominados democráticos- en los 2 años previos a la pandemia, siendo el 2020, año de inicio de la pandemia, cuando más se intensificaron las violaciones. Entre las principales conclusiones se tiene; que existe una caída sostenida del índice de libertades civiles a nivel internacional, indistintamente de la definición política de gobierno y del grado de desarrollo del país. Mientras el control social y el autoritarismo forman parte de la cultura asiática, en los países democráticos, los ciudadanos han cedido libertades sociales en nombre de protección y seguridad ante el contagio.
\end{abstract}

Palabras clave: Control Social. Libertades Sociales. Pandemia.

\begin{abstract}
ABSRACT
The governments of the world, inspired by the strategies of supervision and social immobility created by Chinese authoritarianism, under the pretext of combating the pandemic, have implemented technological tools such as geolocation, facial recognition and manipulation of Big Data, among others, which has strengthened the abuse of individual freedoms. The present research was carried out under a qualitative approach with a documentary review methodology of narrative type, nourished by primary and secondary sources of information. The design was a cross-sectional study conducted in the year 2020 with a non-experimental level. The objective of this work was to know the current state of social freedoms at a global level as a consequence of the application of control strategies and social immobility in the fight against the Covid-19 virus. It was found a downward trend in the index of social freedoms in the world -both in countries with authoritarian governments as well as in those called democratic- in the 2 years prior to the pandemic, being 2020, the year of the beginning of the pandemic, when violations intensified the most. Among the main conclusions is that there is a sustained fall in the index of civil liberties at the international level, regardless of the political definition of government and the degree of development of the country. While social control and authoritarianism are part of Asian culture, in democratic countries, citizens have surrendered social freedoms in the name of protection and security from contagion.
\end{abstract}

Keywords: Social Control. Social Freedoms. Pandemic.

\section{RESUMO}

Os governos do mundo, inspirados pelas estratégias de supervisão e imobilidade social criadas pelo autoritarismo chines, como um pretexto de combater a pandemia, implementaram ferramentas tecnológicas como a geolocalização, o 
reconhecimento facial e a manipulação de Grandes Dados, entre outras, o que reforçou o abuso das liberdades individuais. Esta pesquisa foi realizada sob uma abordagem qualitativa com uma metodologia de revisão documental de tipo narrativo, alimentada por fontes primárias e secundárias de informação. O projeto foi de corte transversal localizado no ano de 2020 com um nível não-experimental. O objetivo deste trabalho era conhecer o estado atual das liberdades sociais em nível global, como consequência da aplicação de estratégias de controle e imobilidade social na luta contra o vírus Covid-19. Nos 2 anos que antecederam a pandemia, foi encontrada uma tendência de queda no índice de liberdades sociais no mundo tanto em países com governos autoritários quanto naqueles chamados democráticos -, sendo 2020, o ano do início da pandemia, quando as violações mais se intensificaram. Entre as principais conclusões está que há uma queda sustentada no índice de liberdades civis em nível internacional, independentemente da definição política de governo e do grau de desenvolvimento do país. Enquanto o controle social e o autoritarismo fazem parte da cultura asiática, nos países democráticos, os cidadãos renunciaram às liberdades sociais em nome da proteção e da segurança contra o contágio.

Palavras-chave: Controle social. Liberdades Sociais. Pandemia.

\section{INTRODUCION}

En la historia de la humanidad, es recurrente ver que en tiempos de convulsión social, política o económica las libertades sociales son el primer objetivo atacado por los gobiernos de turno -con mayor frecuencia en regímenes autoritarios- como muro de contención ante riegos que atenten contra el orden establecido y el poder político. Actualmente se está viviendo un proceso global de control social y de vigilancia ciudadana que impacta negativamente en las libertades sociales, pero esta vez, la causa es un virus. La novedad no está en los gobiernos autoritarios -viejo conocido- sino en la letalidad y rapidez en el contagio que tiene al mundo inmerso en una emergencia sanitaria y, por otra parte, en el uso de las herramientas tecnológicas que le permiten fortalecer el control social, censurar a los medios de comunicación impresos y digitales, anular el uso de redes sociales, como pretexto en el combate contra el virus. El sistema de gobierno chino -creador de estas estrategias- ha introducido una nueva variable, donde no solo utiliza a epidemiólogos e infectólogos, sino a los informáticos y especialistas en la Big Data.

De otro lado, gobiernos democráticos del mundo, se han inspirado en estas prácticas del autoritarismo chino, extrapolándolas a sus países bajo el mismo pretexto, y con el mismo objetivo: lograr el control y la inmovilidad social. Al respecto, (Vommaro, 2020) opina que muchos gobiernos aprovechan esta situación imprevista para profundizar sus rasgos autoritarios y las políticas de descuido de grandes mayorías. En algunos países se instauran estados de sitio o toques de queda, incluso antes que las medidas de prevención o el fortalecimiento de la salud pública. Estas medidas militaristas parecen apuntar a disipar manifestaciones y movilizaciones callejeras. De tal manera que, el control social y el autoritarismo forman parte de la cultura asiática, mientras, en los países democráticos, los ciudadanos han cedido libertades sociales en nombre de protección y seguridad ante el contagio. En tal sentido, la pregunta que guía el objetivo este trabajo de investigación se centra en estos términos ¿Cuál es el impacto que han tenido las medidas de control social promovidas por los gobiernos del mundo, como pretexto de la lucha contra el virus, en las libertades sociales? El presente trabajo se hizo interesante como tema de investigación, ya que es una problemática de mucha actualidad, que está en pleno desarrollo con implicaciones en un derecho humano fundamental como lo son las libertades sociales.

El trabajo tiene la siguiente estructura: En la sección 1 se presenta la Introducción, en la sección 2 se encuentra la Fundamentación Teórica donde se realizó una revisión de literatura afín con el tema 
de investigación, también incluye un análisis de la composición de los sistemas de gobiernos del mundo durante el año de estudio, donde se identifica a los 10 países del planeta donde más se cometieron abusos a las libertades sociales durante el año 2020, en la sección 3 se describe el procedimiento metodológico que se siguió para el desarrollo del trabajo de investigación, seguidamente, en la sección 4 se exponen los resultados encontrados y la discusión que gira en torno al objetivo de la investigación, la cual se pasea por el estado de la libertad global y la libertad en internet a nivel internacional, asi como también, se revisó la situación de las libertades civiles en países con gobiernos, tanto autoritarios como democráticos, finalmente, en la sección 5, se presentan las conclusiones donde se establece la consistencia de los resultados con la pregunta de investigación.

\section{FUNDAMENTACIÓN TEÓRICA}

En la historia de la humanidad, sobre todo en los últimos 100 años, ha sido notorio como en tiempos de convulsión social, política y económica las libertades sociales del hombre se convierten en el primer objetivo a ser atacado por los gobiernos de turno -con mayor frecuencia y rudeza, en regímenes autoritarios- como una vía para tratar de contener cualquier tipo de desestabilización que conlleve a la pérdida del orden establecido y del poder político. Lo anterior, ya es historia conocida como también lo son las pandemias pasadas que ha sufrido la humanidad, a saber; la gripe española (1918-1919) y la gripe asiática (1957-1958) solo por nombrar dos de las más letales en épocas contemporáneas, pero lo que si se constituye en una novedad, por una parte, son las nuevas formas de control político y social que introdujo el gobierno central de China en aras de contener el avance del contagio, ganándose el ¿crédito? de ser el creador de éstas novísimas prácticas de sumisión social y simultáneamente, de cargar con la rémora de ser el país originario del virus. Por otra parte, impresiona, sobre manera, la velocidad sin precedentes con la cual se ha propagado el virus por el planeta entero, trastocando no solo el sistema sanitario internacional, sino todos los órdenes sociales, económicos, culturales y logísticos del mundo, alcanzando niveles de virus globalizado.

En tal sentido, (Valle et ál., 2020) exponen que el Covid-19 ha irrumpido para enseñarnos que los flujos biológicos deben ser tomados en cuenta como un nuevo paradigma de la globalización y más allá de eso, ofrecernos una contundente lección, acerca de lo ciego que fuimos como "Homo Sapiens", sobre todo, a los grandes líderes mundiales y países desarrollados, al pensar que la globalización, solo debía ceñirse a lo comercial, financiero o tecnológico”. Continuando con el análisis, agregan los mismos autores: El partido comunista chino ha aprovechado los efectos de la pandemia para someter al confinamiento total y control social de la población, con el fin de generar censura a los medios de comunicación, anular el uso de las redes sociales y manipulación de la big data, generando un pernicioso precedente como lo es el uso de herramientas tecnológicas que sirven para monitorear, rastrear y vigilar el comportamiento de las personas. Sorprendentemente, muchos países en el mundo han copiado estas prácticas como la receta mágica, poniendo como excusa la lucha para contener al enemigo invisible, representado por el virus SARS COV2.

Llama poderosamente la atención que países paladines de las libertades sociales y líderes de la democracia en el mundo moderno, especialmente, los europeos tales como; Francia, Inglaterra, Alemania y en América, los Estados Unidos y Canadá, entre otros, hayan extrapolado algunos de estos métodos de control social, de una manera transversal y soslayada, tomando en cuenta que provienen de 
un país claramente identificado con ideales totalitarios para incorporarlos en sus propias naciones -de cortes liberales- como métodos de lucha contra la pandemia. En un contexto similar, el historiador israelí Yuval Noah Hariri, autor de 21 lecciones para el siglo XXI ha alertado, junto con otros especialistas, que, si no se tiene cuidado, la epidemia podría marcar "un hito importante en la historia de la vigilancia ciudadana porque podría normalizar el uso de nuevas plataformas digitales, capaces de cambiar nuestro comportamiento y en algunos casos, de predecir nuestras decisiones, y empujarlas hacia diferentes resultados" (El País, 2020).

Entre las practicas que China ha institucionalizado en la cruzada contra el virus y teniendo como sujeto a la ciudadanía y sus libertades sociales, se cuentan; la utilización de cámaras públicas con reconocimiento facial, rastreo a través de teléfonos inteligentes, drones para dar instrucciones sobre la cuarentena a la población y aplicaciones de teléfono para monitorear la salud de los ciudadanos que permiten detectar la temperatura corporal para restringir el movimiento de personas con síntomas. Si bien fue el gigante asiático el primero en utilizar la tecnología como punta de lanza anti pandémica, otro país que también ha utilizado estos mecanismos con relativo éxito ha sido Corea del Sur -país con un sistema de gobierno democrático- que si bien no limitó la movilidad de sus ciudadanos, implementó una amplia red de diagnóstico con el propósito de detectar contagios con el virus en etapas tempranas y utilizó el rastreo de contactos para detectar a cualquier persona que hubiera interactuado con alguien infectado y así ponerlo en cuarentena. (Zastrow, 2020).

Otros países que utilizan el rastreo de personas en cuarentena a través de la instalación de aplicaciones en teléfonos celulares (que pueden estar asociadas a pulseras electrónicas) son Hong Kong, Bahréin y Rusia. Este último país además utiliza cámaras con reconocimiento facial ubicadas en espacios públicos. En Austria, Bélgica y Brasil, a partir de los datos de movilidad captados por las compañías de telefonía celular detectan tanto las tendencias de movilidad como los sitios de mayor aglomeración y, por lo tanto, de mayor potencial de contagio. En Alemania, la empresa Telekom proporciona datos de ubicación de sus clientes a la organización que coordina la acción nacional contra el coronavirus SARS-CoV-2 (Gershgorn, 2020).

Es notorio como el uso de la tecnología- de manera globalizada- ha pasado a ocupar un lugar preponderante en las estrategias para la detención y defensa contra el virus, mientras se hacen los estudios científicos, llámese desarrollo de las vacunas, que permitan abordar la pandemia con un enfoque más epidemiológico, el tema colateral de este asunto es si el control y vigilancia social, que a todas luces, significa un retroceso de las libertades sociales de la personas; ¿es temporalmente necesario como táctica de lucha contra la enfermedad o vino para quedarse? dado la utilidad política que ha significado para los gobiernos.

\subsection{Una mirada al estado de las democracias en el mundo durante la pandemia}

Si bien es cierto, los sistemas democráticos del mundo han estado sometidos a prueba durante los últimos 15 años, la situación pandémica ha impactado en el desenvolvimiento de las democracias mundiales en lo concerniente al respeto de los derechos humanos y a las libertades sociales por parte de los gobiernos de turno. Muchos de los gobiernos democráticos se han inspirado en los métodos utilizados por países autoritarios como China y Rusia para imponer el control social y medidas restrictivas a sus poblaciones, a los medios de comunicación, a la comunidad científica, a los líderes sociales y religiosos, entre otros sectores, colocándose en la situación límite de la transgresión a la raya amarilla de las libertades individuales, bajo la efigie de la lucha contra la pandemia. 
Para conocer un poco más sobre la composición de los sistemas de gobiernos mundiales, en este apartado se presentan algunas cifras extraídas del informe (Democracy Index, 2020) elaborado por la unidad de negocios independiente del Diario Inglés The Economist. El mismo se llevó a cabo sobre una muestra de 167 países del mundo. Para la determinación del índice de democracia, este reporte se basó en cinco categorías: proceso electoral y pluralismo, funcionamiento del gobierno, participación política de la ciudadanía, cultura política y libertades civiles. El resultado de la evaluación de estos indicadores sirvió para definir a los gobiernos en cuatro tipos: "Democracia Perfecta", "Democracia Defectuosa", "Régimen Híbrido" o "Régimen Autoritario". Véase la Tabla 1:

Tabla 1

Tipos de gobiernos en el mundo. Año 2020

\begin{tabular}{|c|c|c|c|}
\hline $\begin{array}{l}\text { Tipo de } \\
\text { gobierno }\end{array}$ & $\mathrm{N}^{\circ}$ de países & \% de países & $\begin{array}{c}\% \text { de la } \\
\text { población } \\
\text { mundial }\end{array}$ \\
\hline $\begin{array}{l}\text { Democracia } \\
\text { Perfecta }\end{array}$ & 23 & 13.8 & 8.4 \\
\hline $\begin{array}{c}\text { Democracia } \\
\text { defectuosa }\end{array}$ & 52 & 31.1 & 41.0 \\
\hline $\begin{array}{c}\text { Régimen } \\
\text { Híbrido }\end{array}$ & 35 & 21.0 & 15.0 \\
\hline \multirow[t]{2}{*}{$\begin{array}{l}\text { Régimen } \\
\text { Autoritario }\end{array}$} & 57 & 34.1 & 35.6 \\
\hline & & & 100 \\
\hline
\end{tabular}

Fuente: Elaboración propia con base al informe Democracy Index (2020)

Se observa en las cifras precedentes que apenas el $8 \%$ de la población mundial vive en paises con sistemas de gobiernos democráticos perfectos, entre tanto, más de un tercio de la misma vive bajo regímenes autoritarios, aglutinados en 57 paises, teniendo el mayor peso en este segmento; China y Rusia que representan el $25 \%$ de la población mundial. Un total de 87 países que representan el $56 \%$ de la población del mundo, viven bajo gobiernos catalogados como democracias defectuosas y regímenes híbridos, estos últimos son sistemas de gobiernos que pendulan entre fachadas democráticas y elementos autoritarios.

En otro trabajo, titulado: Democracy Under Lockdown elaborado por (Freedom House 2020a) basado en una encuesta realizada a 398 periodistas, trabajadores de la sociedad civil, activistas y otros expertos, así como en una investigación sobre 192 países llevada a cabo por la red global de analistas de Freedom House, constituye hasta el momento actual, el primero de su tipo y el esfuerzo más concienzudo con la misión de evaluar la condición de la democracia mundial durante la pandemia. El mismo concluyó que la situación de los derechos humanos y la democracia ha empeorado en 80 países. Los gobiernos han respondido participando en abusos de poder, silenciando a sus críticos y debilitando o cerrando instituciones importantes, a menudo socavando los propios sistemas de rendición de cuentas necesarios para proteger la salud pública. A manera de resumen, la tabla 2 muestra los 10 paises del mundo donde más se cometieron diferentes tipos de abuso. Todos con el mismo objetivo: la restricción de las libertades sociales en aras de luchar contra la situación de emergencia generada por el coronavirus. Asimismo, se puede observar el respectivo estatus de libertad que les fue asignado por Freedom House para el año 2020: 
Tabla 2

Los 10 países donde más se cometieron abusos contra las libertades sociales en el 2020. Tipo de abuso y estatus de libertad

País

Interrupción Restricción a Restricción a

Detenciones Violencia

Estatus de

legislativa

los medios

las protestas

$\mathrm{y}$ arrestos

Política

libertad 2020

India

$\mathrm{X}$

$\mathrm{X}$

$\mathrm{X}$

Libre

Polonia

$\mathrm{X}$

Estados Unidos

$\mathrm{X}$

$\mathrm{X}$

$\mathrm{X}$

Libre

$\mathrm{X}$

Libre

Bolivia

X $\mathrm{X}$

Filipinas

X
$\mathrm{X}$

$\mathrm{X}$

$\mathrm{X}$

$\mathrm{X}$

$\mathrm{X}$

X

$\mathrm{X}$

$\mathrm{X}$

$\mathrm{X}$
$\mathrm{X}$

$\mathrm{X}$

$\mathrm{X}$

$\mathrm{X}$

$\mathrm{X}$

$\mathrm{X}$
Parcialmente

libre

Parcialmente

libre

Sin libertades

Sin libertades

Sin libertades

Sin libertades

Venezuela

Sin libertades

Fuente: Elaboración propia sobre la base de datos de Freedom House 2020

Nótese que los países donde más se cometieron transgresiones contra los indicadores señalados, fueron aquellos catalogados como autoritarios, con estatus "sin libertades o parcialmente libres", los cuales fueron liderados por China, Zimbabue y Turquía, seguidos por Rusia y Venezuela. Asimismo, de los 10 países estudiados, India, Polonia y Estados Unidos, a pesar de mantener su estatus de paises "libres", registraron algunas fallas en contra del sistema de libertades sociales.

Es destacable que en países como China, Rusia y Venezuela donde existen gobernantes con larga data en el poder, las estrategias de subyugación y vigilancia del ciudadano, forman parte intrínseca de las formas de gobierno y de dirección política, por lo que la emergencia sanitaria provocada por el virus les ha permitido poner en práctica métodos de control perfeccionados que por años fueron acariciados como el objetivo final para lograr el dominio y la perpetuación de sus regímenes totalitarios, con la particularidad de haberlo perpetrado bajo tiempos de paz, con muy poca resistencia -por no decir ninguna- so pretexto de la lucha contra la pandemia con la sumisa aceptación de las distintas organizaciones y de sus pobladores. Por su parte, en muchos paises democráticos de Europa y América, (...) "los ciudadanos han cedido libertades a cambio de protección y cobijo, la pandemia posibilita que los ciudadanos depositen su confianza en los gobiernos y sus estrategias, a fin 
de reducir la sensación de incertidumbre o vulnerabilidad asociadas al contagio” (...) (De la Mora, 2020, p.4).

Lo anteriormente descrito, encierra una gran paradoja, ya que nos hace ver como "los extremos se tocan". China y Estados Unidos, países que históricamente han representado dos modelos totalmente antagónicos y disímiles, en lo político, lo económico y social, por añadidura, se configuran como las dos potencias mundiales de la actualidad. El primero, personifica al comunismo recalcitrante y el segundo, al capitalismo puro, por lo que resulta un hecho inusitado observar cómo bajo el crisol de la pandemia, no son tan diferentes en lo que respecta a los procedimientos y estratagemas para materializar el control social y atacar a las libertades individuales, en nombre de la lucha contra el virus, diferenciándose, tan solo, por la intensidad y crueldad de los métodos.

\section{PROCEDIMIENTOS METODOLÓGICOS}

La presente investigación se llevó a cabo bajo un enfoque cualitativo con una metodología de revisión documental de tipo narrativa nutriéndose de fuentes de información primaria y secundaria, a partir de la búsqueda en bases de datos de acceso abierto como Latíndex, Scielo y Google Académico, así como, de revistas especializadas disponibles en la web y repositorios de organizacionales no gubernamentales internacionales que permitieron su recojo, clasificación, procesamiento y posterior análisis. El diseño fue de corte transversal en el tiempo, ubicado en el año 2020 con un nivel no experimental. Este trabajo, tuvo por objetivo conocer el estado actual de las libertades sociales a nivel global como consecuencia de la aplicación de estrategias de control y de inmovilidad social en la lucha contra el virus Covid-19, implementadas por la mayoría de los gobiernos del mundo.

Para ello, se seleccionó una muestra intencionada no probabilística compuesta por 28 países, ( 7 países por cada región del planeta) con base al informe anual elaborado por la Organización Freedom House, denominado Freedom in the World, 2020. Dicho estudio, evaluó a 192 países para luego establecer índices de Libertad Global y Libertad en Internet, los cuales sirven de marco referencial para determinar el puntaje de Democracia de los gobiernos del mundo clasificándolos una escala de: "Países Libres", "Parcialmente Libres" y "Sin libertades".

También, se utilizó como base datos válida para esta investigación, los reportes de Democracy Index de los años 2018, 2019 y 2020, elaborados por la Unidad de Inteligencia del Grupo Consultor The Economist, (EIU) por sus siglas en inglés. El Índice de Democracia de The Economist Intelligence Unit ofrece una rápida visión del estado de la democracia de 165 países en todo el mundo. El Índice de Democracia se basa en cinco categorías: proceso electoral y pluralismo, funcionamiento del gobierno, participación política de la ciudadanía, cultura política y libertades civiles. En función de sus puntuaciones en una serie de indicadores dentro estas categorías, cada país se clasifica a su vez como uno de los cuatro tipos de régimen: "Democracia perfecta", "Democracia imperfecta", "Régimen híbrido" y "Régimen autoritario". Los resultados de ambos análisis, sirvieron para contrastar la pregunta de investigación y son presentados en el siguiente apartado.

\section{RESULTADOS Y DISCUSIÓN}




\subsection{La libertad de expresión y el acceso a la información, ¿otras víctimas de la pandemia?}

La era actual, es una de las etapas más brillantes de la humanidad en cuanto al desarrollo tecnológico, a los grandes avances en las comunicaciones y los sistemas de información, se refiere. Se escriben significativas líneas en la historia presente en el desarrollo del hombre en actividades científicas como la nanotecnología, la inteligencia artificial, la robótica, la energía solar y la electricidad en sustitución de los combustibles fósiles, otro tanto, representan la red de conexión móvil 6G, las tecnologías de reconocimiento facial y la ingeniería espacial con misiones al planeta Marte que ya dejaron de ser una utopía, entre otros logros. Estamos en presencia, pues, de la llamada revolución 4.0 pero resulta contradictorio -hasta el grado de generar un desconcierto generalizado- que en el momento de mayor lucidez y de cambios que suponen un salto cuántico de la evolución humana , un pequeño virus haya llegado para echar por tierra -o al menos ralentizar- todo ese impulso de adelantos que se venía gestando desde hace 2 décadas, poniendo en contexto la vulnerabilidad del hombre como especie y demostrando quien es el verdadero experto en evolución y adaptación a la vida, sobre el planeta tierra.

Esta reflexión sirve para ubicar el análisis objeto de este estudio, acerca del estado de las libertades sociales y su vaso comunicante, como lo es la libertad de expresión. Se aprecia que ambos escenarios están en caída libre -sin la certeza de saber cuánto falta para tocar su punto más bajo- en este momento crucial cuando la humanidad está sufriendo un recrudecimiento de los embates de la pandemia, llamados tercera y cuarta ola de infección trayendo consigo una carga más letal que el brote inicial. A la par de estos eventos, los gobiernos del mundo intensifican las medidas de control sanitario y de inmovilidad social, como armas principales para la contención del virus, mientras comienza la aplicación de las primeras dosis de vacunas de manera simultánea en varios paises, especialmente, en los de ingresos altos.

Debido al confinamiento, gran parte de las actividades del comercio, la educación, el cuidado de la salud y el entretenimiento, entre otras, se han trasladado a entornos on line; bajo la figura de teletrabajo y como expresión de formas de cohabitación del ciudadano, lo que ha convertido a la conectividad de internet más que una opción tecnológica, en una necesidad vital. De otro lado, los gobiernos y los políticos, han encontrado allí, un terreno fértil para crear nuevos sistemas tecnológicos de control social y de censura a los medios de comunicación, tanto escritos como digitales, lo que acrecienta las limitaciones en el acceso a la información. Al respecto, (Germaín, 2020) opina lo siguiente:

\footnotetext{
Durante el período de aislamiento ocurrido de diversos modos en distintos países este efecto de acumulación de información se ha profundizado, se ha extendido en una escala totalmente fuera de nuestro cálculo. De igual manera que escapa a nuestro cálculo las posibilidades de uso de información que se abren en la medida en que dependemos de un modo mucho más intenso que antes de las pantallas, las plataformas, las redes, las aplicaciones para llevar adelante nuestra vida en este tiempo (pp. 147-148).
}

En esa línea, muchas autoridades gubernamentales del mundo, han detenido a líderes religiosos, a migrantes, a directivos de organizaciones no gubernamentales (ONG) y a activistas sociales, acusándolos de tergiversar y confundir a la opinión pública con falsas informaciones. Otro elemento crítico en este proceso de desinformación y control de libertades sociales, es la división social generada por las brechas digitales en los segmentos poblacionales más pobres de los paises, especialmente, en los de ingresos medios y bajos, lo cual convierte a estos grandes grupos de la población en marginados digitales. Así, entonces, algo que venía mal se ha agravado por estos tiempos de pandemia, dejando al 
desnudo, una vez más, las intenciones controladoras de los gobiernos mundiales que atenta contra un derecho humano, como lo es el derecho a la información y a la comunicación.

A los fines de ilustrar este proceso, se presenta la Figura 1, la cual presenta el estado comparativo de las libertades individuales y la libertad de expresión en internet en diversos paises del mundo. La información para su elaboración ha sido recabada con base al informe anual emitido por la organización Freedom House, denominado (Freedom in the World, 2020). El mismo evaluó indicadores como el derecho al voto, la libertad de expresión y la igualdad ante la ley para el caso del índice de Libertad Global (Freedom House, 2020b). Mientras que para el índice de Libertad en internet (Freedom House, 2020c) se evaluaron indicadores tales como; obstáculos en el acceso a la información, censura en los contenidos y violación de los derechos de los usuarios Vale destacar que la figura contiene una muestra de países de ingresos altos, medios y bajos, tanto de tendencias autoritaria como los llamados democráticos en distintos continentes del planeta. La selección fue hecha con la intención de proporcionar una revisión lo más amplia y representativa posible.

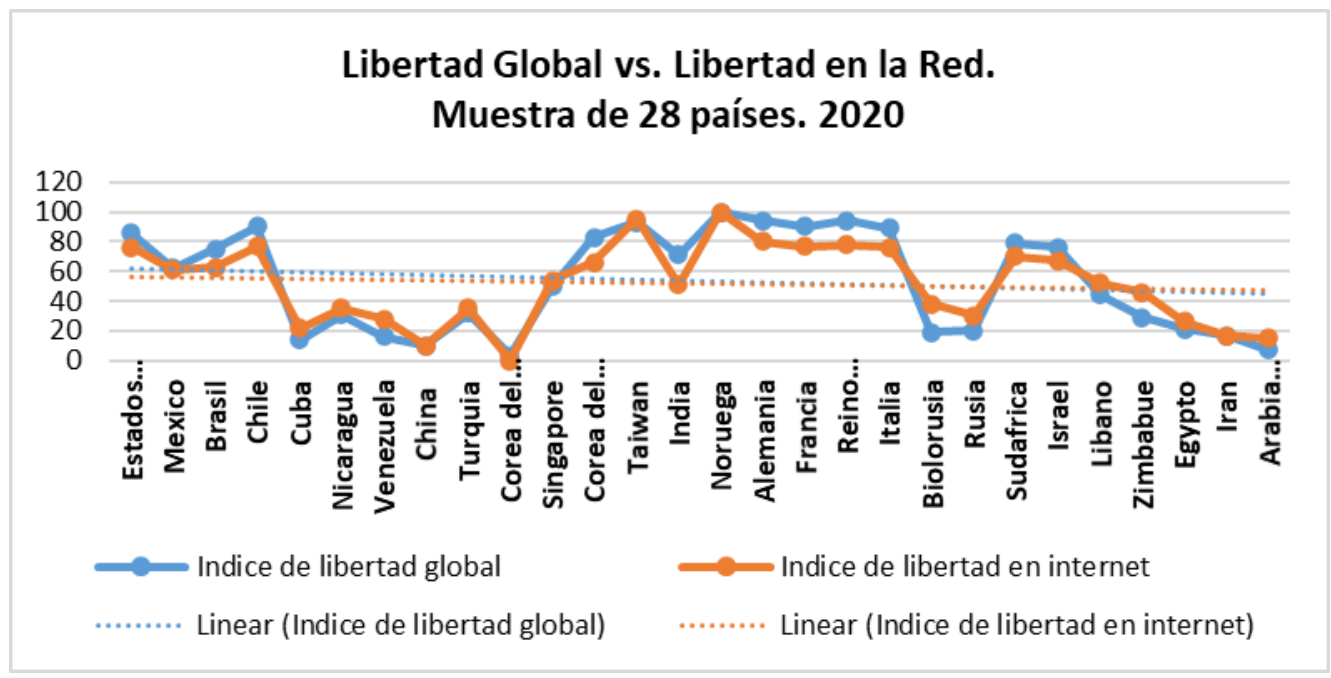

Figura $N^{\circ}$ 1. Fuente: Elaboración propia con base a Freedom House (2020)

Nota: El puntaje para ambos índices se basa en una escala donde " 0 " es el Menos libre y “100” es el Más libre”. Intervalos: Libre: 70-100, Parcialmente Libre: 40-69 y Sin Libertad: 0-39.

La información que se desprende del análisis del informe referido, muestra como el bloque duro de países identificados como autoritarios compuestos por: Corea del Norte, China, Cuba, Venezuela, Nicaragua, Turquía, Bielorrusia, Rusia, Líbano, Zimbabue, Egipto, Irán y Arabia Saudita, en ese orden, reportan los más bajos puntajes en cuanto al índice de Libertad global. Por el contrario, Noruega, con el más alto índice de libertad en el mundo, seguida de Taiwán, Corea del Sur, Chile, los Estados Unidos, Alemania, Francia, el Reino Unido e Italia, mantuvieron durante el año en estudio, los más altos estándares, en tanto que el segundo lugar de este grupo democrático lo conforman México, Brasil, Sudáfrica e Israel. Por otra parte, en lo que respecta al índice de libertad en internet, el desempeño de los indicadores fue similar, así lo demuestra la figura anterior, encontrándose una alta asociación entre ambos indicadores. 
Llama la atención que países incluidos en este análisis como lo son Noruega y Corea del Norte, representan la antítesis de los índices evaluados, el primero con los más altos valores democráticos y el segundo, con el peor desenvolvimiento mundial de este indicador. Al concluir este apartado, se encontró que existe una tendencia generalizada hacia la baja de ambos índices, lo que responde a las preguntas de investigación y permite calificar estos resultados como significativos para este estudio.

\subsection{Las libertades civiles antes y durante la pandemia}

Según la opinión de expertos del área científica-epidemiológica, no se avizora en el corto plazo, el fin de la pandemia Covid-19. Según estimaciones, para el año 2024 es cuando se pudiera lograr la vacunación total de la población mundial, pero nada garantiza la eficacia de la inmunización ya que se han detectado nuevas cepas como la inglesa, la sudafricana y la brasileña -sin descartar que pudieran aparecer nuevas variantes- algo que pudiera tirar por la borda todos los avances logrados hasta ahora al no poder enfrentar con éxito la rapidez de las mutaciones que experimenta el mencionado virus. Esto hace pensar que pudiera mantenerse en el tiempo las restricciones sociales y los ataques a las libertades civiles de los ciudadanos del mundo.

En ese sentido, se hizo una revisión del estado de las libertades civiles a nivel internacional durante este primer año de pandemia, así como de los dos años anteriores a la emergencia sanitaria. Para ello, se tomó la muestra de los mismos 28 paises evaluados en el apartado anterior con la idea de conocer como fue el comportamiento de este indicador en los años que van desde el 2018 al 2020, así como, la clasificación de los paises en el ranking de libertades. Para este segmento, se utilizaron los reportes de Democracy Index de los años mencionados (Democracy Index, 2018; 2019; 2020), como se indica en la Tabla 3:

Tabla 3

Índice de libertades civiles en el mundo

$\begin{array}{lllll}\text { País } & 2018 & 2019 & 2020 & \text { Clasificación } \\ \text { Estados Unidos } & 8.24 & 8.24 & 8.53 & \text { Democracia Imperfecta } \\ \text { México } & 6.18 & 6.18 & 5.88 & \text { Democracia Imperfecta } \\ \text { Brasil } & 8.24 & 8.24 & 7.94 & \text { Democracia Imperfecta } \\ \text { Chile } & 9.12 & 9.12 & 8.82 & \text { Democracia Plena } \\ \text { Cuba } & 2.65 & 2.94 & 2.94 & \text { Régimen Autoritario } \\ \text { Nicaragua } & 4.12 & 4.10 & 3.90 & \text { Régimen Autoritario } \\ \text { Venezuela } & 3.53 & 3.24 & 2.65 & \text { Régimen Autoritario } \\ \text { China } & 1.47 & 1.18 & 1.18 & \text { Régimen Autoritario } \\ \text { Turquía } & 2.35 & 2.35 & 2.35 & \text { Régimen Híbrido } \\ \text { Corea del norte } & 0.00 & 0.00 & 0.00 & \text { Régimen Autoritario } \\ \text { Singapur } & 7.35 & 7.06 & 6.76 & \text { Democracia Imperfecta } \\ \text { Corea del sur } & 8.24 & 8.24 & 7.94 & \text { Democracia Plena } \\ \text { Taiwán } & 9.12 & 9.12 & 7.91 & \text { Democracia Plena } \\ \text { India } & 7.35 & 6.76 & 5.59 & \text { Democracia Imperfecta } \\ \text { Noruega } & 9.71 & 9.71 & 9.71 & \text { Democracia Plena }\end{array}$




\begin{tabular}{clllll} 
& Alemania & 9.41 & 9.41 & 9.12 & Democracia Plena \\
& Francia & 8.53 & 8.53 & 8.24 & Democracia Imperfecta \\
& Reino Unido & 9.12 & 9.12 & 8.82 & Democracia Plena \\
& Italia & 8.24 & 7.94 & 7.94 & Democracia Imperfecta \\
& Bielorrusia & 2.35 & 2.35 & 2.06 & Régimen Autoritario \\
& Rusia & 3.24 & 4.12 & 4.12 & Régimen Autoritario \\
& Sudáfrica & 7.94 & 7.94 & 7.35 & Democracia Imperfecta \\
& Israel & 5.88 & 5.88 & 5.59 & Democracia Imperfecta \\
África- & Líbano & 4.71 & 4.71 & 4.12 & Régimen Híbrido \\
Medio & Zimbabue & 3.24 & 3.24 & 3.24 & Régimen Autoritario \\
Oriente & Egipto & 2.94 & 2.35 & 1.76 & Régimen Autoritario \\
& Irán & 1.47 & 1.47 & 1.47 & Régimen Autoritario \\
& Arabia saudita & 1.47 & 1.47 & 1.47 & Régimen Autoritario \\
\cline { 2 - 5 }
\end{tabular}

Fuente: Elaboración propia con base a Democracy Index (2018; 2019; 2020)

Al realizar el análisis de los resultados encontrados en este apartado, se observa que, en la región del continente americano, se experimentó un deterioro progresivo de las libertades civiles. El indicador regional es arrastrado hacia la baja por paises como México y Brasil, clasificados como democracias imperfectas y, por otra parte, Cuba, Nicaragua y Venezuela con gobiernos de corte autoritario. Entre tanto, los Estados Unidos, logró un ligero avance en este indicador, pero, aun así, esto no impidió que cayera a niveles de democracia imperfecta. Por su parte, Chile, a pesar de una ligera caída, es considerada una democracia plena. En la región asiática, donde se concentra el $40 \%$ de la población mundial, se encontró un franco deterioro de las libertades civiles, encabezado por Corea del Norte -con el peor desempeño del planeta- seguidos de China, Turquía, Singapur y la India, siendo esta región en su conjunto, una de las que presenta peores resultados.

En lo que respecta al continente europeo, se observó que es la región con mejor desempeño en libertades sociales en el mundo. Liderados por Noruega, país que ostenta el más alto estándar de este indicador a nivel global, secundada por Alemania y el Reino Unido, en la calificación de democracias plenas. Llama la atención que Francia e Italia, cayeron a la clasificación de democracias imperfectas. En otro, extremo, se encontró que Rusia y Bielorrusia, antiguos miembros de la extinta Unión Soviética, son clasificados como gobiernos autoritarios. En tanto que, las regiones de África y Medio Oriente, arrojaron los peores desempeños globales. Cabe destacar, que estas son las únicas regiones del planeta donde no existe al menos, una democracia plena. Sudáfrica e Israel, dos con la mejor clasificación, son considerados como democracias imperfectas, en tanto que el resto de los países, son regímenes híbridos y autoritarios; Líbano, Zimbabue, Egipto, Irán y Arabia Saudita.

La Figura 2, ilustra la tendencia hacia la baja del índice de Libertades sociales en el mundo, tanto en los 2 años previos a la pandemia, es decir 2018 y 2019 como en el 2020, año de inicio de la pandemia, propiamente dicho. Los resultados encontrados para este indicador, son consistentes con los resultados que arrojó el análisis de la Libertad de expresión y la Libertad en la red, revisados en el apartado anterior. Estos hallazgos marcan una clara tendencia negativa en la evolución de dichos indicadores a nivel global. 


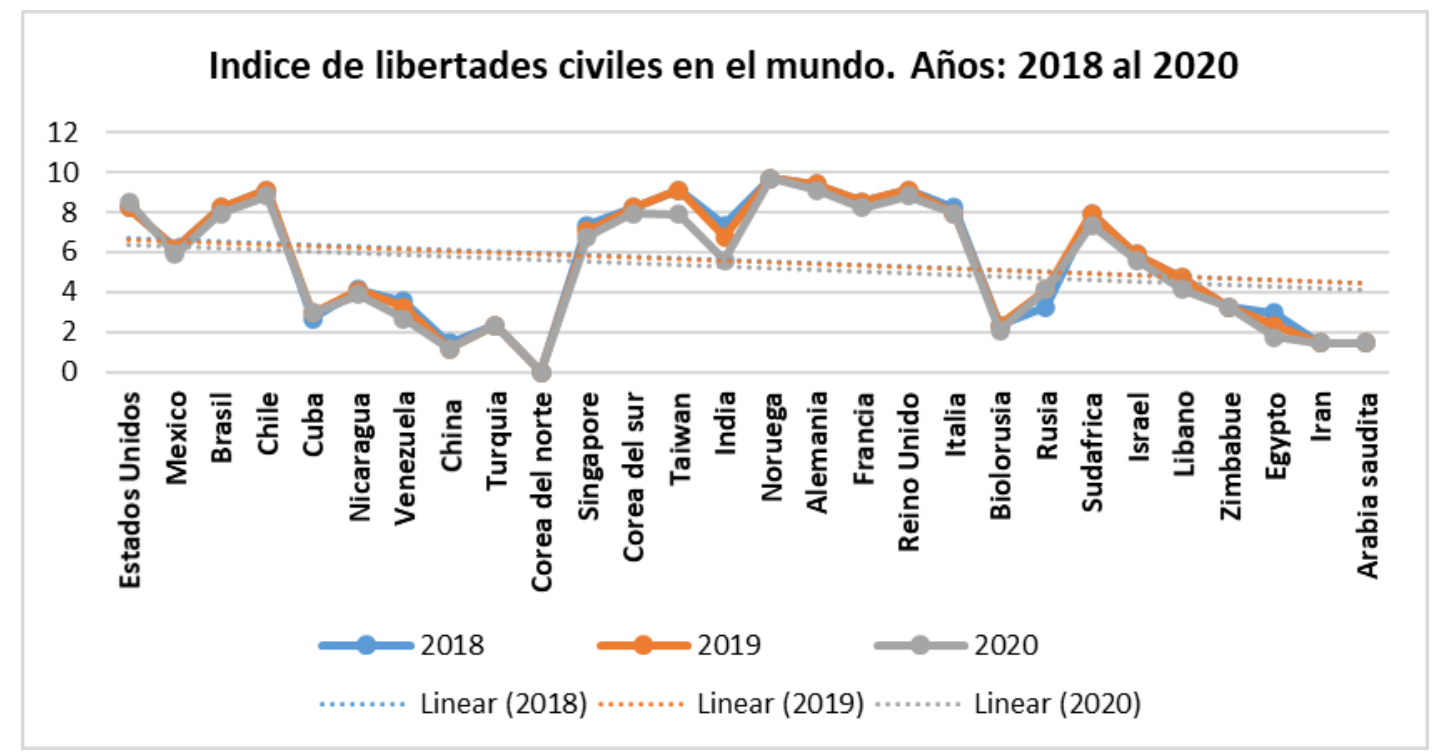

Figura 2. Fuente: Elaboración propia con base a Democracy Index $(2018,2019,2020)$

\section{CONCLUSIONES}

Los resultados son bastante claros para concluir que la tendencia general en el desempeño del índice de libertades civiles a nivel internacional es de una caída sostenida en su valoración, lo que se traduce en una creciente debilidad en su gestión gubernamental-institucional, indistintamente de su definición política y de su nivel de desarrollo. En lo que se refiere a las limitaciones encontradas para este trabajo, se tiene que existe muy poca producción científica sobre este tema específico del retroceso de las libertades sociales en tiempos de pandemia, más allá de la información que ofrecen las organizaciones no gubernamentales y los organismos multilaterales, pudiera inferirse que es debido a la actualidad del problema, el cual está en pleno desarrollo -aunque las proyecciones son bastante significativas- aún no se puede prever con certeza, cuando será el término de esta emergencia sanitaria y su desenlace final. En lo que respecta a las hipótesis de trabajo, siguiendo el enfoque cualitativo basado en revisión de la literatura con un análisis narrativo, no se realizó comprobación sistemática, sino más bien lo que se persigue con este trabajo es generar teoría en aras de fundamentar próximas investigaciones.

Lo que constituye una realidad concluyente, es el accionar de los gobiernos de signos autoritarios y otros inspirados por espíritus nacionalistas, tanto de izquierda como de derecha, quienes han sucumbido ante la tentación del control social y la inmovilidad ciudadana. Es conocido que esto es una práctica política muy común entre los gobiernos autoritarios que fue extrapolada por los sistemas de gobiernos democráticos como una estrategia "exitosa" creada en China a los fines de combatir la emergencia sanitaria generada por el virus Covid-19. Dicha estrategia, se afianza en la tecnología como herramienta principal de monitoreo y vigilancia, introduciendo una nueva variable; ya no solo son 
necesarios los epidemiólogos e infectólogos, sino también, los informáticos y los especialistas en Big Data para enfrentar las pandemias.

En trabajo de (Contursi, 2020) se encuentran similitudes conclusivas con la presente investigación. Expone dicho autor que después de estudiar una muestra de 33 paises, con sistemas de gobiernos liberales y autoritarios, distribuidos entre Asia, América y Europa, se pudo concluir que existe una alta correlación positiva de las variables de estudio, a saber, "Democracia Liberal" y "Libertades Civiles", en los paises con gobiernos democráticos, pero con una proyección a desmejorar. Mientras que, en los paises con gobiernos autoritarios, estos indicadores arrojaron resultados bajos. De manera contraria, los resultados de las variables "Protección a la privacidad" y "Capacidad del gobierno para regular la internet”, fueron mucho más altos en estos últimos paises y ostensiblemente, más bajos en paises democráticos.

Lo anterior, en palabras de Han, (2020) es posible debido a que Estados asiáticos como Japón, Corea, China, Hong Kong, Taiwán o Singapur tienen una mentalidad autoritaria, que les viene de su tradición cultural (confucianismo). Las personas son menos renuentes y más obedientes que en Europa. También confían más en el Estado. Y no solo en China, sino también en Corea o en Japón la vida cotidiana está organizada mucho más estrictamente que en Europa. Sobre todo, para enfrentarse al virus los asiáticos apuestan fuertemente por la vigilancia digital. Sospechan que en el big data podría encerrarse un potencial enorme para defenderse de la pandemia (p.99). Visto lo anterior, nacen las dudas, si el control social, que es parte inmanente del modus vivendi de los asiáticos ¿Por qué entonces, los gobiernos liberales del mundo, copiaron transversalmente gran parte de sus métodos de control ciudadano sin tomar en cuenta que son prácticas ajenas a los pueblos democráticos? Siendo que encierran una gran dosis de esa cultura oriental, donde no se reconocen las libertades civiles como genuinas expresiones de democracia.

A propósito de estas reflexiones, una vez superado este evento pandémico cabría preguntarse: ¿Serán China y sus aliados con su modelo autoritario conculcador de libertades, los grandes vencedores y la democracia mundial, la gran perdedora como predicen algunos? o por el contrario ¿los sistemas democráticos saldrán fortalecidos por su capacidad de promover consensos y libertad social? A este respecto, la opinión de la politóloga feminista Saara Saarma citada por (Huotari y Teivainen, 2020) pudiera arrojar algunas luces, cuando dice que hay una posibilidad de que el mundo post coronavirus (post-coronial) sea ligeramente más postcolonial. Pero también, aprender de China puede conllevar una difusión más extendida de técnicas de control autoritarias. Para el futuro democrático, en sus diversas posibilidades, la crisis del coronavirus presenta tanto peligros como oportunidades (p.77).

Los planteamientos descritos líneas arriba, abren las puertas a futuras investigaciones que permitirían abordar temas sobre los riesgos que envuelven a la crisis de salud global actual de convertirse en una crisis social, precipitada por la pérdida de libertades civiles y políticas, lo que a la postre, desencadenaría un estadio superior de crisis de derechos humanos a nivel mundial. En ese sentido el programa conjunto sobre el VIH/SIDA de las naciones unidas (ONUSIDA), alerta a la comunidad internacional cuando expresa:

Si bien las leyes de derechos humanos permiten la limitación o derogación de algunos derechos para fines legítimos, como proteger la salud pública, existen límites estrictos sobre cuándo, cómo y en qué medida los derechos pueden estar limitados. Cualquier limitación debe ser por un objetivo legítimo y debe ser proporcional a ese objetivo, necesario, con plazos límites, no arbitrarios ni discriminatorios y de acuerdo con la ley. (2020, p.5) 
En ese mismo orden de ideas la Cámara Interamericana de Derechos Humanos (CIDH) emitió la resolución 1/2020, literal 3, ordinal f, donde enfatiza:

Aún en los casos más extremos y excepcionales donde pueda ser necesaria la suspensión de determinados derechos, el derecho internacional impone una serie de requisitos - tales como el de legalidad, necesidad, proporcionalidad y temporalidad-dirigidos a evitar que medidas como el estado de excepción o emergencia sean utilizadas de manera ilegal, abusiva y desproporcionada, ocasionando violaciones a derechos humanos o afectaciones del sistema democrático de gobierno. (2020, p.9)

Finalmente, la gran duda estriba en si la implementación de mecanismos de vigilancia y control ciudadano han llegado para quedarse o si, por el contrario, se podrá avizorar en el corto plazo, el fin de la pandemia y con ello, el punto final de las prácticas autoritarias que atentan contra las libertades civiles de los ciudadanos del mundo.

\section{REFERENCIAS}

Cámara Interamericana de los Derechos Humanos (CIDH). (2020). Pandemia y Derechos Humanos en las Américas. Recuperado de: https://www.oas.org/es/cidh/decisiones/pdf/Resolucion-1-20-es.pdf

De la Mora, G. (2020) Aislamiento social y vigilancia para contener la pandemia or Covid-19, algunas acciones de gobiernos y actores sociales. Centro Regional de Investigaciones Multidisciplinarias CRIM. No 26 junio 2020. Universidad Nacional Autónoma de México. (UNAM). p.4. Recuperado de: http://ru.crim.unam.mx/handle/123456789/66

Freedom House (2020a). Democracy Under Lockdown. Recuperado de: https://freedomhouse.org/report/specialreport/2020/democracy-under-lockdown

Freedom House (2020b). Global Freedom Score. Recuperado de: https://freedomhouse.org/countries/freedom-world/scores

Freedom House (2020c). Internet Freedom Score. Recuperado de: https://freedomhouse.org/countries/freedom-net/scores

Germaín, M. (2020) Pandemia, redes sociales y gobiernos de las emociones. Rep Hip UNR. Universidad Nacional De Rosario. (UNR) Argentina. Recuperado de: http://rephip.unr.edu.ar/handle/2133/18864

Gershgorn, D. (9/4/2020). We Mapped How the Coronavirus Is Driving New Surveillance Programs Around the World. One Zero. Recuperado de: https://onezero.medium.com/the-pandemic-is-a-trojan-horse-for-surveillance-programsaround-the-world-887fa6f12ec9

Han, B. (24/03/2020). La Emergencia Viral y el Mundo del Mañana. Diario El País. Recuperado de: https://elpais.com/ideas/2020-03-21/la-emergencia-viral-y-el-mundo-de-manana-byung-chul-han-el-filosofosurcoreano-que-piensa-desde-berlin.html

Hariri, Y.N. (22/03/2020). La Mejor Defensa Contra los Patógenos, es la Información. El País de España. Recuperado de: https://elpais.com/cultura/2020-03- 21/yuval-noah-harari-la-mejor-defensa-contra-los-p atogenos-es-lainformacion.html

Huotari, P. y Teivainen, T. (2020). Gobernanza Global y Horizontes Democráticos más allá del Coronavirus. En Blinger, B. y Pleyers, G. (Eds.) Alerta Global. Políticas, movimientos sociales y futuros en disputa en tiempos de Pandemia. p.77. Finlandia. Fundación: Biblioteca Clacso. Recuperado de: http://biblioteca.clacso.edu.ar/clacso/se/20200826014541/Alerta-global.pdf 
ONUSIDA. Programa Conjunto de las Naciones Unidas (ONU) sobre el VIH/SIDA (2020). Los Derechos Humanos en Tiempos de Covid-19. Recuperado de: https://www.unaids.org/sites/default/files/media_asset/human-rights-andcovid-19_es.pdf

The Economist. Intellingence Unit. (2018). Democracy Index 2018. ¿Me too? Recuperado de: https://275rzy1ul4252pt1hv2dqyuf-wpengine.netdna-ssl.com/wpcontent/uploads/2019/01/Democracy_Index_2018.pdf

The Economist. Intellingence Unit. (2019). Democracy Index 2019. A year of Democracy set backs. Recuperado de: https://www.in.gr/wp-content/uploads/2020/01/Democracy-Index-2019.pdf

The Economist. Intellingence Unit. (2020). Democracy Index 2020. In Sickness and in Health Recuperado de: file:///C:/Users/MANAGER/Downloads/democracy-index-2020\%20(1).pdf

Valle, F., Vega, F., Morocho, J., Gutierrez, J. y Reyes, M. (2020). Covid-19: lecciones tempranas de un nuevo paradigma en el proceso de globalización. Journal of Research and Opinion. DOI: https://doi.org/10.15520/jro.v7i4.61

Vommaro, P. (2020). Durante y después de la pandemia: dimensiones sociales, políticas y económicas. En Blinger, B. y Pleyers, G. (Eds.) Alerta Global. Políticas, movimientos sociales y futuros en disputa en tiempos de Pandemia. p.167. Finlandia. Fundación: Biblioteca Clacso. Recuperado de: http://biblioteca.clacso.edu.ar/clacso/se/20200826014541/Alerta-global.pdf

Zastrow, M. (2020). Coronavirus contact-tracing apps: can they slow the spread of COVID-19? Nature Research Journal. DOI: https://doi.org/10.1038/d41586-020-01514-2 